\title{
Nonunion of the tibia following intramedullary nailing treated by Ilizarov external fixator: A case report
}

\author{
Davut Keskin*, Adem Erkut, Mehmet Sabri Balık, Yılmaz Güvercin \\ Department of Orthopaedics and Traumatology, Faculty of Medicine, Recep Tayyip Erdoğan University, Rize, Turkey
}

\section{ARTICLE INFO}

Article History

$\begin{array}{ll}\text { Received } & 25 / 12 / 2012 \\ \text { Accepted } & 22 / 01 / 2013\end{array}$

\section{* Correspondence to:}

Davut Keskin

Department of Orthopaedics and Traumatology,

Faculty of Medicine,

Recep Tayyip Erdoğan University,

Rize, Turkey

e-mail: keskind2002@yahoo.com

\section{Keywords:}

Ilizarov

Intramedullary nail

Nonunion

Tibia

\section{ABSTRACT}

Nonunion may be encountered, though occasionally, following fixation of long bone (such as tibia) fractures with an intramedullary nail. Despite availability of several treatment options in such situations, none seems to be ideal. In this study, we reported a case with aseptic tibia nonunion which was treated with Ilizarov external fixator over the intramedullary nail, which is a relatively novel modality with few studies available, and we proposed the method as an effective one with emphasis on further studies to explore the method.

J. Exp. Clin. Med., 2013; 30:175-177

\section{Introduction}

Nonunion following intramedullary nailing of long bone fractures is a unique problem. Application of Ilizarov external fixator over the nail is a relatively novel technique for such nonunions, emerging as an alternative treatment method with lack of sufficient scientific studies and data on it (Patel et al., 2000; Menon et al., 2002; Brinker and O'Connor, 2003). In this study, we aimed to extend present knowledge by presenting a case who developed atrophic tibia nonunion despite the intramedullary nail fixation and who was treated via monofocal Ilizarov compression over a nail.

\section{Case}

A 34-year old man was admitted to the hospital with a diagnosis of short oblique closed fracture on the midshafts of the right tibia and fibula resulting from a vehicle accident. Proximally locked dynamic reamed intramedullary nailing was performed via closed method. In order to permit axial loading, distal end of the nail was not locked to the tibia. The patient began weight bearing on his affected leg on the first postoperative day. He suffered from pain around the fracture site upon walking even one year after the operation, and plain radiographs revealed a gap of 2-3 $\mathrm{mm}$ and a nonunion of distrophic type (Winquist et al., 1984) (Fig. 1). We did not determine any causes of pseudoarthrosis. Clinical, laboratory and radiological findings were not consistent with infection. There upon the patient was reoperated and Ilizarov external fixator was applied in a manner to form two each rings on the proximal and distal of the fracture region. The fibula was osteotomized obliquely from the former fracture location. Intramedullary nail was not touched and left as it was (Fig. 2).

Monofocal compression of $0.25 \mathrm{~mm}$ per day was applied starting from the postoperative first day. Progress of bony contact was monitored by anteroposterior and lateral plain radiographs. Compression was terminated on the $15^{\text {th }}$ day when full bony contact occurred as determined by radiology. Bony union was found sufficient in post-operative $7^{\text {th }}$ month (Fig. 3 ) and the external fixator was removed. The follow-up period for the patient was two years, and the latest situation of the bony union as observed in plain radiographs is given in Fig. 4. 


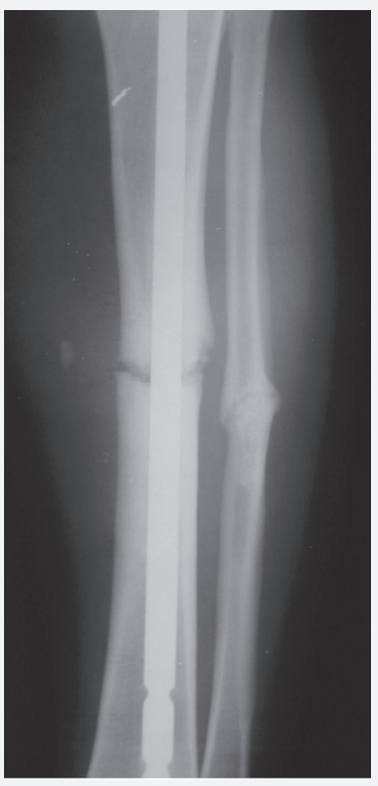

Fig. 1. A

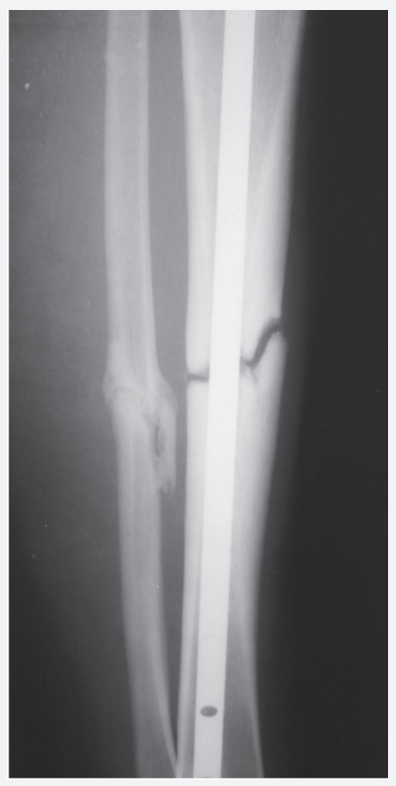

Fig. 1. B
Fig. 1. Atrophic nonunion of the tibia following intramedullary nailing is seen on anteroposterior (a) and lateral (b) plain radiographs

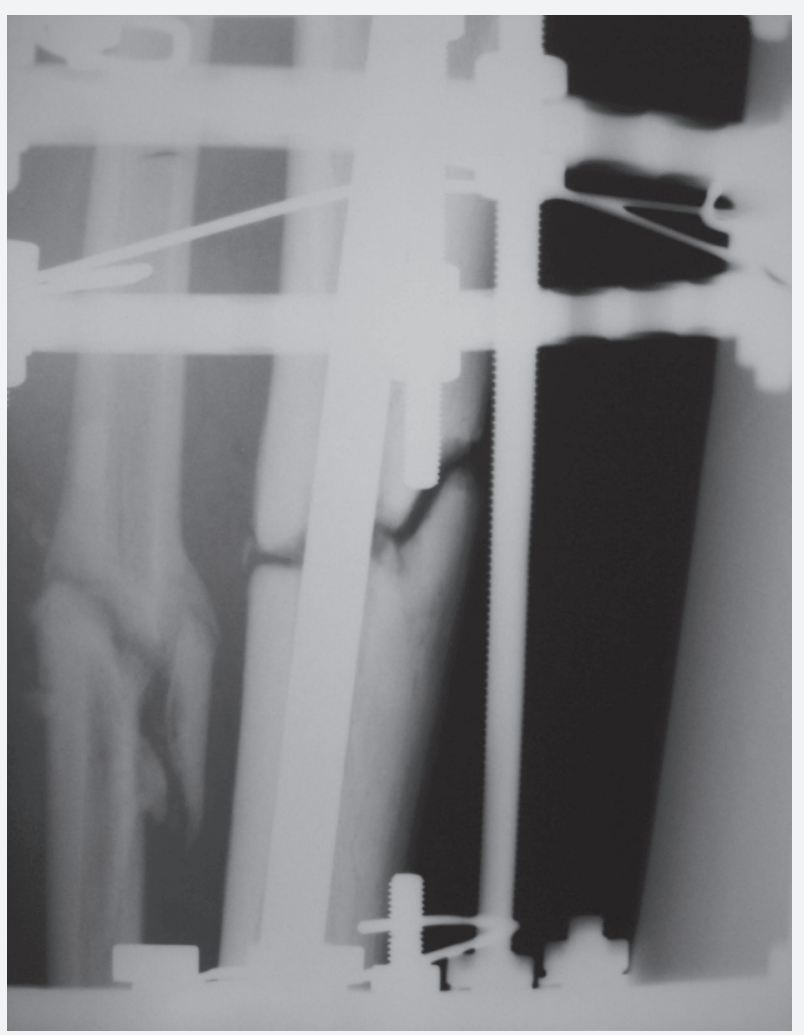

Fig. 2. Presented radiograph shows the Ilizarov external fixator applied over the intramedullary nail

\section{Discussion}

Nonunion may present itself as a problem, though occasionally, following intramedullary fixation of the tibial fractures (Zelle et al., 2004; Patil and Montgomery, 2006; Sen et al., 2006). Too much or too little motion at the fracture site, excessive space between fracture fragments, inadequate fixation, infection, soft tissue interposition, inadequate blood supply,

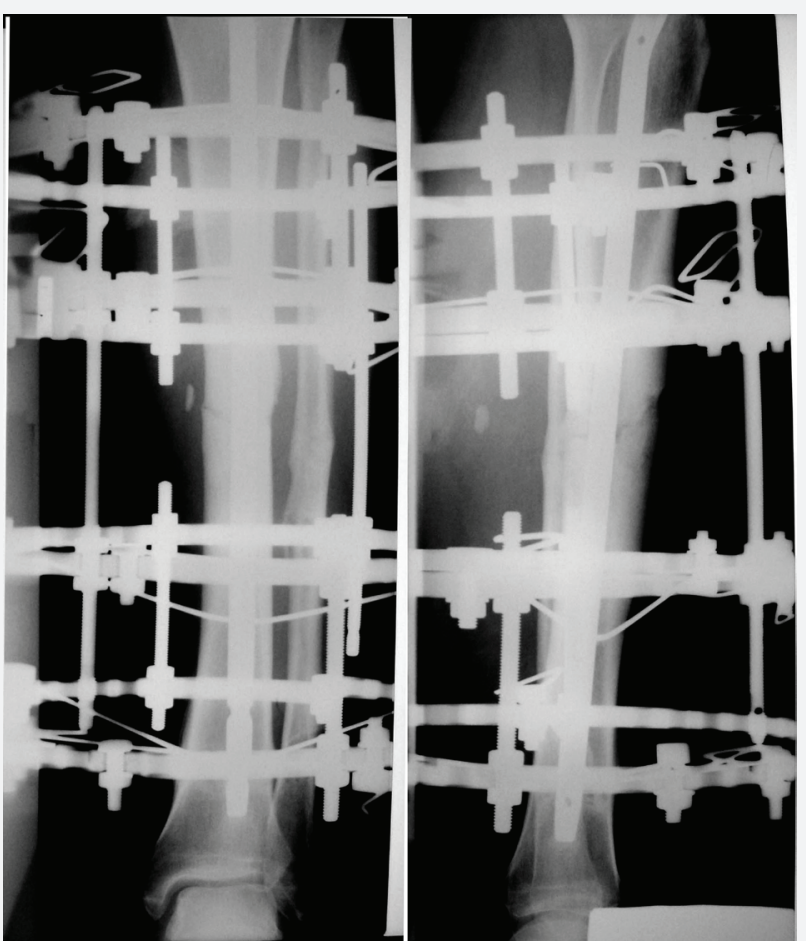

Fig. 3 A

Fig. 3 B

Fig. 3. Anteroposterior (a) and lateral (b) radiographs in postoperative 7 th month

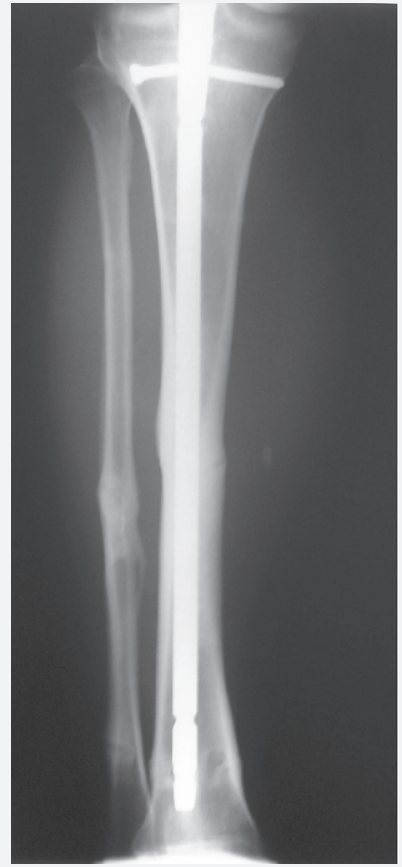

Fig. 4A

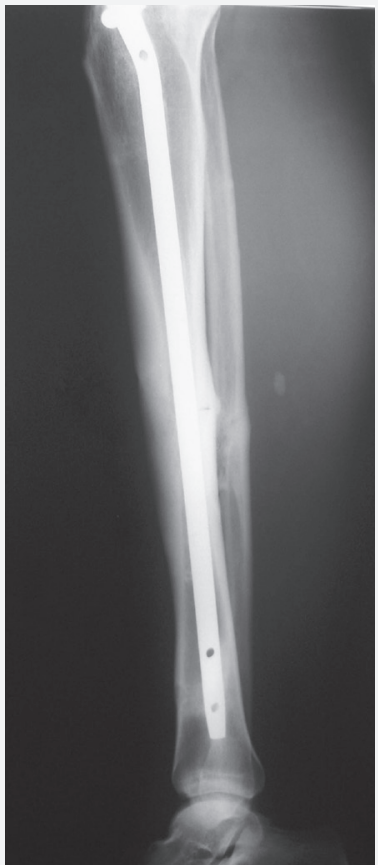

Fig. 4 B
Fig. 4. Anteroposterior (a) and lateral (b) final radiographs (postoperative 2nd year) show solid bony union

and many other factors can lead to nonunion (Shuler 1996; Rosen 1998; Audige et al., 2005; Drosos et al., 2006). Our patient had not any well-known causes of pseudoarthrosis.

A variety of treatment modalities can be preferred in such a situation including replacement of the nail with a largerdiameter nail, dynamization of replaced nail, open reduction 
and internal fixation by plates and screws, bone grafting or grafting other materials with osteogenic potential on the fracture site, electrical simulation or low-intensity pulsed ultrasound, and application of external fixator by removing the nail (Shuler 1996; Rosen 1998; Mayr et al., 2000; Zelle et al., 2004; Patil and Montgomery, 2006; Sen et al., 2006). Each of these methods has advantages and disadvantages.

Treatment of aseptic nonunions by applying Ilizarov external fixator over intramedullary nail is a relatively new technique, not sufficiently explored yet. Very few researchers used the technique on limited number of cases, with published successful results (Patel et al., 2000; Menon et al., 2002; Brinker and O'Connor, 2003). It is possible in the method either to apply Ilizarov external fixator over the intramedullary nail that has originally been placed by keeping the nail in its position, or fixator may be applied by replacing the original nail with another nail having a smaller diameter (Brinker and O'Connor, 2003). The aim here is to slide the bone over the nail in order to compress fracture ends and to induce bony union. When the nail is too tight to prevent sliding the bone over it, it may be replaced with a smaller one.

In our case, which was an atrophic type tibia nonunion, the original nail was left in place and an external fixator was applied over it in order to ensure the treatment, and the fracture was allowed to heal without the need of additional support. In our opinion the technique, currently with very limited findings published, will be used more widely as studies progress to explore it. Leaving the intramedullary nail in its place will ensure a good compression by preventing translocation and shear forces. A further important advantage of the technique is that the nail protects fracture site until full bony union is achieved, without requiring an external support after removal of the external fixator (Brinker and O'Connor, 2003). Pin-track infection leading to deep intramedullary infection is a serious complication of the procedure. To avoid this problem, external fixation wires are inserted without their coming into contact with the intramedullary nail (Paley et al., 1997).

We believe that this technique, which prevents soft tissue damage in fracture location, reduces blood loss, shortens operation time, ensures a good mechanic stability and reduces the need for additional osteogenic materials such as bone graft, is an efficient method in the treatment of aseptic nonunions developing following intramedullary nail fixation.

\section{REFERENCES}

Audige, L., Griffin, D., Bhandari, M., Kellam, J., Ruedi, T.P., 2005. Path analysis of factors for delayed healing and nonunion in 416 operatively treated tibial shaft fractures. Clin. Orthop. Relat. Res. 43, 221-232.

Brinker, M.R., O'Connor, D.P., 2003. Ilizarov compression over a nail for aseptic femoral nonunions that have failed exchange nailing: A report of five cases. J. Orthop. Trauma. 17, 668-676.

Drosos, G.I., Bishay, M., Karnezis, I.A., Alegakis, A.K., 2006. Factors affecting fracture healing after intramedullary nailing of the tibial diaphysis for closed and grade I open fractures. J. Bone Joint Surg. Br. 88, 227-231.

Mayr, E., Frankel, V., Ruter, A., 2000. Ultrasound-an alternative healing method for nonunions? Arch. Orthop. Trauma Surg. 120, 1-8.

Menon, D.K., Dougall, T.W., Pool, R.D., Simonis, R.B., 2002. Augmentative Ilizarov external fixation after failure of diaphyseal union with intramedullary nailing. J. Orthop. Trauma. 16, 491-497.

Paley, D., Herzenberg, J.E., Paremain, G., Bhave, A., 1997. Femoral lengthening over an intramedullary nail. J. Bone Joint. Surg Am. 79, 14641480.

Patel, V.R., Menon, D.K., Pool, R.D., Simonis, R.B., 2000. Nonunion of the humerus after failure of surgical treatment. Management using the Ilizarov circular fixator. J. Bone Joint Surg. Br. 82, 977-983.

Patil, S., Montgomery, R., 2006. Management of complex tibial and femoral nonunion using the Ilizarov technique, and its cost implications. J. Bone Joint Surg. Br. 88, 928-932.

Rosen, H., 1998. Nonunion and malunion. In: Skeletal Trauma, Vol. 1, $2^{\text {nd }}$ ed. B.D. Browner, J.B. Jupiter, A.M. Levin, P.G. Trafton, eds. WB Saunders, Philadelphia, pp. 619-660.

Sen, C., Eralp, L., Gunes, T., Erdem, M., Ozden, V.E., Kocaoglu, M., 2006. An alternative method for the treatment of nonunion of the tibia with bone loss. J. Bone Joint Surg. Br. 88, 783-789.

Shuler, T.E., 1996. Trauma: Complications-delayed union/nonunion. In: Review of Orthopaedics, 2nd ed. M.D. Miller, ed. WB Saunders, Philadelphia, pp. 351-354.

Winquist, R.A., Hansen, S.T.Jr., Clawson, D.K., 1984. Closed intramedullary nailing of femoral fractures. A report of five hundred and twenty cases. J. Bone Joint Surg. Am. 66, 529-539.

Zelle, B.A., Gruen, G.S., Klat, B., Haemmerle, M.J., Rosenblum, W.J., Prayson, M.J., 2004. Exchange reamed nailing for aseptic nonunion of the tibia. J. Trauma. 57, 1053-1059. 